\title{
Prosthetic valve thrombosis: Twenty-year experience at the Montreal Heart Institute
}

\author{
Nicolas Dürrleman, $\mathrm{MD}^{\mathrm{a}}$ \\ Michel Pellerin, MD \\ Denis Bouchard, MD \\ Yves Hébert, $M D^{\mathrm{a}}$ \\ Raymond Cartier, $\mathrm{MD}^{\mathrm{a}}$ \\ Louis P. Perrault, MD, PhD \\ Arsène Basmadjian, $M D^{\mathrm{b}}$ \\ Michel Carrier, $\mathrm{MD}^{\mathrm{a}}$
}

Background: Prosthetic valve thrombosis is a life-threatening complication. We reviewed the incidence, risk factors, and treatment strategies of this rare complication.

Methods: From February 1981 through January 2001, 5430 valve operations were performed in 4924 patients at the Montreal Heart Institute. Of this cohort, 39 patients presented with prosthetic valve thrombosis and had complete follow-up data obtained from our prospective valve clinic database.

Results: In this series $82 \%$ of patients were women, and the mean age was $58 \pm 11$ years. The underlying pathology involved the mitral valve in $75 \%$ of cases. Most prosthetic valve thromboses occurred with mechanical prostheses (95\%). The time interval from first valve replacement to prosthetic valve thrombosis was $39 \pm 42$ months. The most frequent clinical presentation was severe congestive heart failure (44\%). On prosthetic valve thrombosis presentation, the international normalized ratio was less than 2.5 in 54\%, with inadequate anticoagulation management in $26 \%$ and poor compliance in $26 \%$. Eighty-two percent of patients underwent a surgical procedure, consisting of thrombectomy in $47 \%$, mitral valve replacement in $47 \%$, and aortic valve replacement in $6 \%$ of patients. The 30-day operative mortality and total in-hospital mortality after prosthetic valve thrombosis were $25 \%$ and $41 \%$, respectively. The 10-year actuarial survival after prosthetic valve thrombosis was $46 \% \pm 10 \%$.

Conclusion: Inadequate level of anticoagulation is the most important factor involved in the pathogenesis of prosthetic valve thrombosis. The overall mortality rate despite surgical treatment remains high. This study underscores the importance of meticulous surveillance of anticoagulation therapy in patients with prosthetic valves.

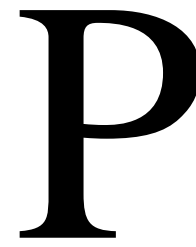

rosthetic valve thrombosis (PVT) is defined by any thrombus, in the absence of infection, attached to or near an operated valve, occluding part of the blood flow or interfering with valvular function. ${ }^{1}$ This rare but life-threatening complication of prosthetic valve replacement is dependent on valve design (tilting disc valves and caged ball valves), structure (mechanical valves), and location (mitral position) and patient compliance with oral anticoagulation. The 11-year probability of PVT is $0.01 \%$ to $0.02 \%$ for patients with either type of valve in the mitral or aortic position. ${ }^{2}$ Tilting disc mechanical valves ${ }^{3}$ have most often been implicated, although this complication can be found with any type of valve prosthesis. Diagnosis is often 
established late and sometimes only at autopsy. ${ }^{4}$ Multiple causes ranging from inadequate anticoagulation ${ }^{5,6}$ to pannus formation ${ }^{7}$ have been identified. Surgical treatment includes thrombectomy and valve replacement.

The purpose of this report is to review the clinical experience with the medical and surgical management of PVT in a large surgical cohort of patients undergoing valve replacement at the Montreal Heart Institute.

\section{Materials and Methods}

From February 1981 through January 2001, 5430 valve operations were performed in 4924 patients. From this cohort, $39(0.8 \%)$ patients were rehospitalized for PVT. The clinical records prospectively gathered by a specialized team at the local valve clinic were reviewed. Preoperative clinical data, initial valve procedure, diagnostic features of valve thrombosis, and management before, during, and after the operation were recorded. The incidence of valve thrombosis according to valve localization was analyzed. Several factors were analyzed to define the risk factors for PVT development, including sex, aortic versus mitral position, and singleversus double-valve replacement.

\section{Clinical Data at the Initial Operation}

Thirty-nine patients presented with PVT, 7 (18\%) men and 32 $(82 \%)$ women (Table 1). Mean age at the time of PVT diagnosis was $58 \pm 11$ years. Sixteen (41\%) patients were in atrial fibrillation before the initial valve replacement, and $4(10 \%)$ patients had a permanent pacemaker. Thirty-four (87\%) patients were in New York Heart Association (NYHA) functional class III or IV before the first valve replacement. The initial pathology involved the mitral valve in $29(75 \%)$ cases, whereas aortic valve disease and double-valve disease (mitral and aortic) accounted for $4(10 \%)$ and $6(15 \%)$ patients of the cohort, respectively. The first valve replacement was a redo intervention in $8(21 \%)$ patients. Eleven $(28 \%)$ patients presented with a history of prior thromboembolic complications, including retinal artery thrombosis, leg ischemia, stroke, pulmonary embolism, or left atrial appendage thrombosis.

At least one risk factor for thromboembolism (coagulation disorder, autoimmune systemic disease, or neoplasia) was present in $7(18 \%)$ patients. Lupus erythematosus was diagnosed in 2 patients.

Left atrial diameter measured by means of echocardiography was $53 \pm 13 \mathrm{~mm}$ at the time of the first intervention. Preoperatively, cardiac dyskinesia was identified in 13 (33\%) patients by means of transthoracic echocardiography (TTE) or ventriculography.

\section{Initial Valve Surgery}

Most initial valve replacements were performed with Carbomedics prostheses $(72 \%)$, including one patient having a tricuspid valve replacement with a Carbomedic prosthesis for severe tricuspid regurgitation. Left atrial appendage resection was performed in 2 $(5 \%)$ patients. Postoperative left ventricular ejection fraction was greater than $45 \%$ in most patients (26/31 [84\%]). Mean initial intensive care unit length of stay was $5 \pm 4$ days, and mean hospital stay was $13 \pm 7$ days.
TABLE 1. Clinical data

\begin{tabular}{lr}
\hline & $\begin{array}{c}\text { No. of } \\
\text { patients (\%) }\end{array}$ \\
\hline Sex & \\
Female & $32(82)$ \\
Male & $7(18)$ \\
Coronary artery disease & $6(15)$ \\
Hypertension & $8(21)$ \\
Diabetes & $2(5)$ \\
Preoperative rhythm (initial intervention) & \\
Atrial fibrillation & $16(41)$ \\
Pacemaker & $4(10)$ \\
Preoperative NYHA class (initial intervention) & \\
Class III-IV & $34(87)$ \\
Initial pathology & \\
Mitral & $29(75)$ \\
Aortic & $4(10)$ \\
Mitral and aortic & $6(15)$ \\
Prior thromboembolism & $11(28)$ \\
Presence of a thromboembolism risk factor & $7(18)$ \\
\hline
\end{tabular}

NYHA, New York Heart Association.

\section{Anticoagulation Protocol}

Anticoagulation was initiated 48 hours after all valvular procedures (heparin and warfarin). When aspirin was added to the anticoagulation regimen, it was started on postoperative day 1 . Patients were discharged with an international normalized ratio (INR) in the target range of 2.5 to 3.5 and were followed at the anticoagulation clinic.

\section{Statistical Analysis}

Data are expressed as means \pm SDs or medians when appropriate. Univariate analysis was performed with the Student $t$ test for parametric data and the Pearson $\chi^{2}$ test for proportions. Analysis of survival was performed by using the Kaplan-Meier method. The statistical analyses were performed with NCSS 2001 (NCSS Statistical Software, Kaysville, Utah).

\section{Results}

\section{Thrombosis}

The distribution of PVTs according to the site of valve implantation was as follows: $26(67 \%)$ mitral, $6(15 \%)$ aortic, $6(15 \%)$ double, and $1(3 \%)$ tricuspid replacement. PVT involved mechanical prostheses in $25(96 \%)$ of 26 instances in the mitral position and in 5 (83\%) of 6 valves in the aortic position. The only thrombosis of a tricuspid valve was with a mechanical prosthesis.

Among double-valve prosthesis recipients (6 patients), PVTs were in the mitral prosthesis in $5(83 \%)$ patients, and a bivalvular thrombosis was seen in $1(17 \%)$ patient. In the mitral valve replacement group, more patients had atrial fibrillation than in the aortic valve replacement group (46\% vs $0 \%, P=.04)$. In the aortic position only $50 \%(3 / 6)$ were considered eligible for a surgical procedure after PVT diagnosis versus $88 \%(23 / 26)$ in the mitral position $(P=.03)$. 
TABLE 2. Diagnosis of valve thrombosis

\begin{tabular}{lc}
\hline & $\begin{array}{c}\text { No. of } \\
\text { patients }(\%)\end{array}$ \\
\hline Early thrombosis $(<30 \mathrm{~d})$ & $8(21)$ \\
Late thrombosis $(>30 \mathrm{~d})$ & $31(79)$ \\
Main diagnosis sign & \\
Dyspnea & $22(56)$ \\
Shock & $5(13)$ \\
Auscultation & $5(13)$ \\
Others & $6(15)$ \\
Fortuitous & $1(3)$ \\
Prior thromboembolism & $9(23)$ \\
INR $<2.5$ during thrombosis & $21(54)$ \\
Trigger factor & $10(26)$ \\
Compliance & $10(26)$ \\
Perioperative of another procedure & $2(5)$ \\
Dysrhythmia & $9(23)$ \\
Multiple causes & $8(20)$ \\
Unknown &
\end{tabular}

INR, International normalized ratio.

\section{Diagnosis of PVT}

The mean interval between the first valve replacement and the occurrence of PVT was $39 \pm 42$ months (range, 0-120 months). There were $8(21 \%)$ early thromboses $(<30$ days after the first valve replacement) and 31 (79\%) late thromboses. The median time between the diagnosis of PVT and surgical treatment was 2 days (range, 0-138 days; 2 days in late PVT and 2.5 days in early PVT).

Symptoms at presentation were dyspnea in $22(56 \%)$ patients, modification of heart murmur in $5(13 \%)$ patients, cardiogenic shock in $5(13 \%)$ patients, and miscellaneous symptoms (abdominal pain, syncope, or stroke) in $6(15 \%)$ patients. In one patient PVT was a fortuitous echocardiographic finding. The majority of patients (34 [87\%]) with PVT were in NYHA functional class III or IV at the time of diagnosis. Two patients were in respiratory-cardiac arrest, and 1 patient was undergoing mechanical ventilation and considered to be NYHA functional class IV. Overall, the most frequent clinical finding was congestive heart failure (17 [44\%] patients). Occurrence of thromboembolism (stroke or limb or organ ischemia) between initial valve replacement and the occurrence of valve thrombosis was reported in $9(23 \%)$ patients.

The diagnosis of PVT was made with TTE in 21 (54\%) patients, transesophageal echocardiography in $8(21 \%)$ patients, and angiography in $3(8 \%)$ patients. The diagnosis was established in $2(5 \%)$ patients in the operating room and in $5(13 \%)$ patients at postmortem examination. The INR recorded at the time of thrombosis was less than 2.5 in 21 (54\%) patients (Table 2).

\section{Precipitating Factors of PVT}

PVT occurred during preparation or recovery from another surgical procedure, requiring changes in the anticoagulant treatment and level in $10(26 \%)$ patients. Poor patient compliance with the anticoagulant treatment leading to lower INR than recommended was responsible for another 10 (26\%) PVT episodes. New atrial arrhythmias (atrial fibrillation) were observed in $2(5 \%)$ other patients with PVT. Multiples factors were probably operative in 9 (23\%) patients specifically related to the association of poor compliance and the appearance of a new atrial arrhythmia. No specific cause was identified in $8(21 \%)$ patients.

Atrial fibrillation was present in $45 \%$ (14/31) of patients with late valve thrombosis versus $25 \%$ (2/8) of those with early PVT $(P=.01)$. Pannus formation was present along with the thrombus at the time of the operation in 50\% (19/38) of patients, and this was more frequent in those with late valve thrombosis $(18 / 30[60 \%])$ than in those with early PVT (1/8 [13\%]; $P=.01)$.

\section{Thrombus}

The characteristics of thrombi were reviewed in 38 of 39 patients. Thrombi were found in the left atrium in $16(16 / 38$ [42\%]) patients, in the left ventricular cavity in $1(1 / 38$ [3\%]) patient, and in both cavities in 21 (21/38 [55\%]) patients. In patients with aortic valve thrombosis, $29 \%(2 / 6)$ had thrombi on the aortic side only, and $71 \%(4 / 6)$ had thrombi in the left ventricle.

Pathologic findings showed that the thrombus was fresh in $34 \%(13 / 38)$, old in $13 \%(5 / 38)$, and had both characteristics in 53\% (20/38) of patients. Old and fresh thrombi were defined according to pathologic structural organization.

Thrombi were larger than $5 \mathrm{~mm}$ in $89 \%$ (34/38), mobile in $58 \%(22 / 38)$, and obstructive in $89 \%(34 / 38)$.

\section{Management of Patients With PVT and Early Mortality}

All patients were started on intravenous heparin as soon as the diagnosis was suspected. Six (15\%) of 39 patients received thrombolytic therapy during $23 \pm 21$ hours (range, $0-48$ hours) by using streptokinase in 5 patients and rTPA in another patient. Thrombolysis was attempted as a definitive treatment in $5(83 \%)$ patients because of the poor general medical condition of the patients. In 1 patient thrombolysis was used to allow an improvement of cardiac performance to enable the transfer to our tertiary care center.

In the thrombolysis group $(\mathrm{n}=6), 2(33 \%)$ patients died, one from cardiogenic shock and one from hemorrhagic stroke. Three (50\%) patients were redirected toward surgical intervention after failure of thrombolysis, and another was transferred to the operating room while receiving the thrombolytic treatment.

Overall, 5 patients died before reaching the operating room in the earlier part of the experience. The thrombotic event occurred before the use of thrombolysis. 
In the surgical group 28 patients underwent emergency operations without prior thrombolysis, and 4 patients underwent operations after thrombolysis. Two patients died immediately on chest opening without possible resuscitation, and one patient could not be weaned from cardiopulmonary bypass $(3 / 32[9 \%])$.

A redo median sternotomy was used in $27(84 \%)$ of 32 patients, and a right anterolateral thoracotomy was performed in 5 patients. Video-assisted thrombectomy of the prosthesis was performed in 14 (47\%) of 30 patients treated surgically, and valve replacement was required in $16(53 \%)$ of 30 patients. When the thrombosed prosthetic valve was replaced, simultaneous thrombectomy of cardiac cavities was performed. One patient had a mitral replacement and a concomitant thrombectomy of the right atrium. Among the 16 patients who underwent valve replacement, 14 had mitral valve replacement and 2 underwent aortic valve replacement. All patients with early PVT underwent video-assisted thrombectomy without the necessity for valve replacement. The crossclamping time averaged $75 \pm 32$ minutes (range, 16-133 minutes), and the cardiopulmonary bypass time was $118 \pm 48$ minutes (range, 31-217 minutes).

The operative mortality rate was $9 \%$ (3/32). Overall, hospital mortality of all patients with valve thrombosis was $41 \%$ (16/39). The overall hospital mortality was higher in the early PVT group (6/8 [75\%]) compared with that in the late PVT group (10/31 [32\%]; $P=.03)$.

Cardiac complications occurred in $14 \%$ (4/29; low cardiac output, cardiogenic shock, complete atrioventricular block, and tamponade), 21\% (6/29) presented with multiple organ dysfunction, $10 \%$ (3/29) experienced a neurologic complication (stroke), and coagulopathy occurred in 7\% (2/29).

\section{Postoperative Care}

The oral anticoagulation regimen after surgical treatment of PVT consisted of warfarin alone in 14 (14/25 [56\%]) patients and a combination of warfarin and aspirin in 11 (11/25 [44\%]) patients (dose range, 80-325 $\mathrm{mg}$ die). The mean hospital stay was $13 \pm 9$ days (range, 3-48 days), and the mean intensive care unit stay was $7 \pm 9$ days (range, 1-48 days).

\section{Long-term Survival and Recurrence of PVT}

The 10-year actuarial survival rate was $46 \% \pm 10 \%$ (Figure 1). The cause of long-term death was sudden death in 3 patients. Three patients had recurrence of valve thrombosis and died ( 2 after rereplacement and one after thrombectomy). Two had severe left ventricular dysfunction, and one had a hypercoagulation status associated with an autoimmune disease.

Among the 14 patients who underwent prosthetic thrombectomy, 8 remain long-term survivors without valvular reintervention.

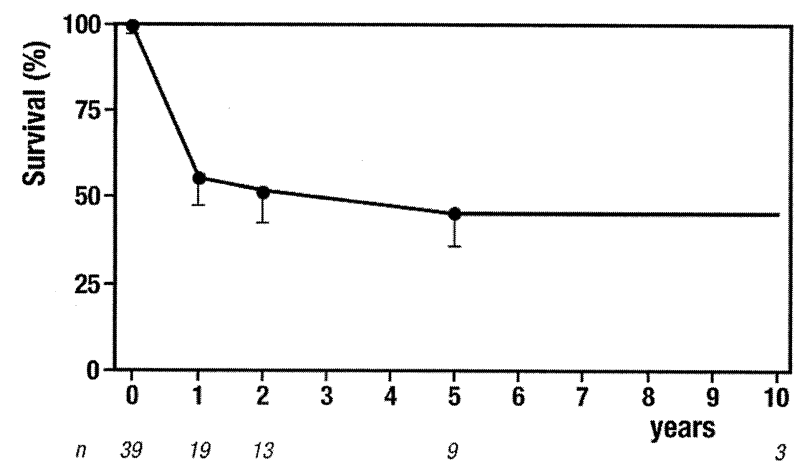

Figure 1. Survival after initial valve replacement surgery.

\section{Discussion}

The present study suggests that surgical intervention should be performed in most patients with PVT after the shortest possible delay between diagnosis and the intervention. Thrombolysis appears only useful as a medical bridge to an operation. PVT thrombolysis did not have a good rate of success in our group of patients as a primary treatment. The second observation of this study is that PVT could be prevented in most patients with better management of the anticoagulation treatment.

Valve thrombosis is a rare but lethal complication of valvular prosthetic replacement. ${ }^{8,9}$ The clinical presentation varies from insidious dyspnea to cardiac arrest. Establishing the diagnosis might be quite difficult, and some series have been reported as being made at postmortem examination in up to $50 \%$ of cases. ${ }^{4}$ In a recent study the delay between first symptoms to hospitalization ranged from 1 to 45 days. ${ }^{10}$ Previous studies have shown that a delay in diagnosis and long duration of symptoms resulted in a higher mortality. ${ }^{11}$ Clinical examination is a poor diagnostic tool. ${ }^{12}$ A normal TTE scan with a strong clinical suspicion of PVT dictates an extensive investigation with transesophageal echocardiography. ${ }^{13}$

Mechanical valves, tilting disc vales, caged ball valves, mitral position, and poor patient compliance with the anticoagulation treatment are the most frequently related risks factors for PVT reported in the literature. Buttard and colleagues ${ }^{10}$ found inadequate systemic oral anticoagulation at the time of diagnosis in 45\%: $27 \%$ for medical reasons (surgical intervention, neurologic events, or pregnancy) and $17 \%$ because of poor patient compliance. A direct relationship has already been established between inadequate anticoagulation and valve thrombosis by several authors, as is suggested in the present study. ${ }^{14-16}$

Early PVT was associated with a worse prognosis and significantly higher in-hospital rates compared with those with late occurrence of the thrombotic event.

Pannus formation, defined as an excessive wound fibrosis around a prosthetic valve, has recently been studied in 
patients with $\mathrm{PVT}^{7,17}$ and could be found in $25 \%$ of patients as early as the first postoperative month. ${ }^{10}$ In the present series the precise role of pannus in the pathogenesis of valve thrombosis remains unknown, but it was found to be more frequent in female patients, in patients with late thrombosis, and in survivors. The presence of pannus was correlated with a better prognosis and is a definite indication for prosthetic valve rereplacement.

Several studies have examined the role of thrombolysis in the management of PVT. ${ }^{18,19}$ Recently, Roudaut and coworkers ${ }^{20}$ conducted a retrospective study of 110 patients treated with fibrinolytic therapy and concluded that the treatment should be reserved for selected patients (those with tricuspid thrombosis, critically ill patients, and patients with contraindications to surgical intervention).

In our experience thrombolysis is indicated in those who could not tolerate cardiopulmonary bypass and those with severe hemodynamic compromise to improve cardiac function and to allow transfer to a tertiary care center for definitive surgical treatment.

On the basis of the present experience, patients with PVT should undergo emergency surgery. Valve thrombectomy is performed in patients with fresh thrombi related to recent change in the anticoagulation management, and valve replacement is done in all other patients. If patient compliance with the medication at long term is an issue, a bioprosthetic valve should be implanted. When thrombectomy is performed, the ventricular cavity is inspected with a videothoracoscope. ${ }^{21}$ A laryngeal mirror can also be useful in this situation. Prosthetic thrombectomy is a safe, rapid, and simple procedure in a limited number of patients. Before discharge, aspirin (80-325 mg die) is added to warfarin treatment. By optimizing the level of anticoagulation and by helping endothelialization of the prosthetic valve, aspirin might improve survival.

Mortality in patients with PVT remains high. The most common precipitating factors for valve thrombosis are inadequate anticoagulation and poor patient compliance, underscoring the need for both patient- and physician- oriented education. Although less invasive than surgical intervention, thrombolysis can be reserved for patients necessitating transfer to a tertiary care center. Surgical intervention remains the mainstay of treatment for patients with PVT.

We thank Ismael El Hamamsy, MD, and Louis-Mathieu Stevens, MD, for their precious help in this work.

\section{References}

1. Edmunds LH Jr, Clark RE, Cohn LH, Grunkemeier GL, Miller DC, Weisel RD. Guidelines for reporting morbidity and mortality after cardiac valvular operations. Ad Hoc Liaison Committee for Standardizing Definitions of Prosthetic Heart Valve Morbidity of The American
Association for Thoracic Surgery and The Society of Thoracic Surgeons. J Thorac Cardiovasc Surg. 1996;112:708-11.

2. Hammermeister KE, Sethi GK, Henderson WG, Oprian C, Kim T, Rahimtoola S. A comparison of outcomes in men 11 years after heart-valve replacement with a mechanical valve or bioprosthesis. Veterans Affairs Cooperative Study on Valvular Heart Disease. N Engl J Med. 1993;328:1289-96.

3. Nunez L, Iglesias A, Sotillo J. Entrapment of leaflet of St. Jude medical cardiac valve prosthesis by minuscule thrombus: report of two cases. Ann Thorac Surg. 1980;29:566-9.

4. Kontos GJ Jr, Schaff HV, Orszulak TA, Puga FJ, Pluth JR, Danielson GK. Thrombotic obstruction of disc valves: clinical recognition and surgical management. Ann Thorac Surg. 1989;48:60-5.

5. Sivasubramanian S, Vijayshankar CS, Krishnamurthy SM, Santhosham R, Dwaraknath V, Rajaram S. Surgical management of prosthetic valve obstruction with the Sorin tilting disc prosthesis. $J$ Heart Valve Dis. 1996;5:548-52.

6. Mustapha R, Philip I, Bohm G, Depoix JP, Enguerand D, Debauchez $\mathrm{M}$, et al. Thrombosis of heart valve prostheses: favourable and prognostic factors based on a study of 41 patients. Ann Chir. 1994;48: 243-7.

7. Deviri E, Sareli P, Wisenbaugh T, Cronje SL. Obstruction of mechanical heart valve prostheses: clinical aspects and surgical management. J Am Coll Cardiol. 1991;17:646-50.

8. Cannegieter SC, Rosendaal FR, Briet E. Thromboembolic and bleeding complications in patients with mechanical heart valve prostheses. Circulation. 1994;89:635-41.

9. Horstkotte D, Burckhardt D. Prosthetic valve thrombosis. J Heart Valve Dis. 1995;4:141-53.

10. Buttard P, Bonnefoy E, Chevalier P, Marcaz PB, Robin J, Obadia JF, et al. Mechanical cardiac valve thrombosis in patients in critical hemodynamic compromise. Eur J Cardiothorac Surg. 1997;11:710-3.

11. Tsai KT, Lin PJ, Chang CH, Chu JJ, Chang JP, Kao CL, et al. Surgical management of thrombotic disc valve. Ann Thorac Surg. 1993;55:98101.

12. Kontos GJ Jr, Schaff HV. Thrombotic occlusion of a prosthetic heart valve: diagnosis and management. Mayo Clin Proc. 1985;60:118-22.

13. Gueret P, Vignon P, Fournier P, Chabernaud JM, Gomez M, LaCroix $\mathrm{P}$, et al. Transesophageal echocardiography for the diagnosis and management of nonobstructive thrombosis of mechanical mitral valve prosthesis. Circulation. 1995;91:103-10.

14. Massad M, Fahl M, Slim M, Haddad R, Dagher I, Alam S, et al. Thrombosed Bjork-Shiley standard disc mitral valve prosthesis. J Cardiovasc Surg (Torino). 1989;30:976-80.

15. Venugopal P, Kaul U, Iyer KS, Rao IM, Balram A, Das B, et al. Fate of thrombectomized Bjork-Shiley valves. A long-term cinefluoroscopic, echocardiographic, and hemodynamic evaluation. J Thorac Cardiovasc Surg. 1986;91:168-73.

16. Butchart EG, Lewis PA, Grunkemeier GL, Kulatilake N, Breckenridge IM. Low risk of thrombosis and serious embolic events despite lowintensity anticoagulation. Experience with 1,004 Medtronic Hall valves. Circulation. 1988;78(suppl):I66-77.

17. Rizzoli G, Guglielmi C, Toscano G, Pistorio V, Vendramin I, Bottio T, et al. Reoperations for acute prosthetic thrombosis and pannus: an assessment of rates, relationship and risk. Eur J Cardiothorac Surg. 1999;16:74-80.

18. Roudaut R, Labbe T, Lorient-Roudaut MF, Gosse P, Baudet E, Fontan $\mathrm{F}$, et al. Mechanical cardiac valve thrombosis. Is fibrinolysis justified? Circulation. 1992;86(suppl 5):II8-5.

19. Roudaut R, Lafitte S, Roudaut MF, Perron JM, Labeque JN, Pradeau $\mathrm{V}$, et al. Fibrinolysis and thrombosis of mechanical valvular prosthesis: risk stratification by transesophageal echocardiography. Arch Mal Coeur Vaiss. 2002;95:897-902.

20. Roudaut R, Lafitte S, Roudaut MF, Courtault C, Perron JM, Jais C, et al. Fibrinolysis of mechanical prosthetic valve thrombosis: a singlecenter study of 127 cases. J Am Coll Cardiol. 2003;41:653-8.

21. Carrier M, Pellerin M, Dagenais F, Perrault LP, Petitclerc R, Pelletier LC. Videoassisted thrombectomy of mechanical prosthetic heart valves. J Heart Valve Dis. 1999;8:404-6. 